\title{
Comparing the Fluidity, Recall Power, Achievement Motivation and Educational Attainment of Students in Smart and Ordinary Schools in
} Physics 1

\author{
Mostafa Ghane Ardekani, ${ }^{1}$ and Faezeh Nateghi ${ }^{2,}$ \\ ${ }^{1}$ Islamic Azad University of Arak, Arak, Iran \\ ${ }^{2}$ Department of Educational Sciences, Islamic Azad University of Arak, Arak, Iran \\ "Corresponding author: Faezeh Nateghi, Assistant Professor, Department of Educational Sciences, Islamic Azad University of Arak, Arak, Iran, E-mail: f-nateghi@iau-arak.ac.ir
}

Received 2014 July 08; Revised 2016 February 29; Accepted 2016 March 09.

\begin{abstract}
Background: Nowadays, educational systems need schools that provide continuous learning and new opportunities for people to experience life in the information society by using information and communications technology. This study aimed to compare the fluidity, recalling power, educational attainment motivation and educational attainment of students in smart and ordinary schools in physics 1.

Methods: This was a causal-comparative study, the subjects of which included 56 high school boys of Arak District 2. Abedi creativity test, Herman educational attainment test and a researcher-made test were used to assess groups. Face validity of tests was confirmed by 5 experts in physics and 5 in education and training field. To assess the reliability exam fluidity, the correlation coefficient (0.95) was used. Two methods were used to test the reliability of the achievement motivation test including Cronbach's alpha (0.87) and split-half. In split-half method, the Spearman-Brown correlation coefficient formula (0.72) was used. Test-retest method was used to determine the reliability of the tests. The correlation coefficient between the results obtained from two tests was 0.96. Data were analyzed using SPSS statistical software version 20 and descriptive statistics, two-sample t-parametric tests at $95 \%$.

Results: Findings showed that there is a significant difference between the mean scores of the fluidity of the experimental group (38.14) and the control group (41.71) $(\mathrm{P}=0.027)$. Moreover, there was a significant difference between the mean recalling scores of the experimental group (4.42) and the control group (5.80) $(\mathrm{P}=0.002)$. However, there was no significant difference between the mean scores on educational attainment in experimental group (39.18) and control group (41) $(\mathrm{P}=0.09)$. Furthermore, no significant difference was observed between the mean score of educational attainment (12.23) and the control group (13.25) $(\mathrm{P}=0.395)$.

Conclusions: Creativity, recalling power of students in traditional classroom physics 1 was more than the smart classroom at the end of the school year. Moreover, there was no significant difference between the two classes regarding the educational attainment and the achievement motivation.
\end{abstract}

Keywords: Smart Schools, Creativity, Motivation, Educational Achievement, Physics, Reminder

\section{Background}

A new era in social well known as intelligence community has started, which has affected the human life, its relations, education and mission. Today, the main concern of the education system of a country is to provide an appropriate ground for the growth and development of intellectual capital and knowledge-based society. Today, the education system needs schools enabling continuous learning and provide new opportunities for people to experience life in the information society by using information and communication technology (ICT), so that this technology is not only as a tool, but also is considered as an infrastructure for education and professional training (1). ICT is one the change factors in classrooms and its role and influence on the development of knowledge and in facilitating and accelerating learning is irrefutable in our times (2). In fact, ICT is a part of the movement towards a better use of modern educational technology in schools. Making broad use of ICT in the education process along with the evolution of educational approaches has led to the establishment of smart schools (3). These schools are among the key requirement of knowledge-based societies and are associated with approaches to the development of entrepreneurship skills of students and teachers. Smart schools pursue objectives including increasing the participation of elements associated with the school system, especially parents, educators and students and providing higher level of interaction among them. On the other hand, students become familiar with electronic technology in such schools thereby increasing their individual abilities. In these schools, teaching - learning process is reinforced and an integrated interactive environ- 
ment is provided to improve key skills of students with an emphasis on group activities in a knowledge-based era. Moreover, students realize the importance and relevance of the courses to life outside the classroom; therefore students are motivated to learn more. The inclusive growth is one of our intended goals, since by dominating all the system and receiving feedback from the progress trend of students; they clearly recognize their strengths and weaknesses and help fix the system problems. Diversification and getting out of the monotonous and traditional teaching methods is among the goals which can increase the work efficiency in schools if the plan is in implemented; In these schools, students with any level of ability and talents can make use of the provided content .Students get familiar with the importance of time in the system and learn how well they can achieve their desires through the use of communication technologies (4). Another reason for the use of ICT in education is to help advance the education quality, which is done by increasing learners' motivation to learn using multimedia softwares integrating text, sound and motion pictures. These softwares can create authentic content and facilitate the acquisition of basic skills by engaging students in the learning process. They also create underlying concepts of the higher level thinking skills and creativity (5). Unlike traditional training, ICT training is based on the student's self-learning (6). Since one of the problems today in the field of education is lack of interest of students to learn, especially in physics and in order to study the factors affecting student learning improvement, researches should be conducted in the field of information and communication technology, especially in relation to basic courses such as physics, in which knowledge acquisition and progress is the groundwork for sustainable development in any country. Therefore, students should be motivated to learn to this course (physics) using a new method (7). According to the results of the previous researches in connection with the use of ICT in education, it can be said that one of the ways to create interest in the students of toward physics is the use of ICT. Nowadays, computer approaches are widely used in teaching physics. ICT can make physics more interesting, accurate and better, provides more opportunities for observation, discussion and analysis, provides more opportunities for communication and cooperation, and as a tool, give students more independence in scientific research and positively affect the teaching and learning process. To use ICT in teaching physics, Internet or CDs can be used as information sources to gather scientific information from digital cameras and video camera to record events. Moreover, spreadsheets and graphical tools can be used to analyze the data. Animations and virtual environments are good tools for simulation and modeling. Emails, portable de- vices like laptops; technologies like presentation technologies such as data projectors, interactive boards are useful tools for teaching and learning. Given the importance of animation in learning, PowerPoint program can be used to better understand lessons (5). Dorothy et al., conducted a research on the effect of using softwares on physics learning in one of the high schools in Malaysia and came to the conclusion that the use of educational technology affects the learning process (8). In a study titled effectiveness of ICT-based education at different levels and courses, Barrow and et al., concluded that the performance of the students trained in computer was dramatically better than those learn using the traditional method (9). Deryakulu et al. conducted another study titled predicting successfully teaching students with ICT teaching with different learning styles in Turkey; Statistical analysis of the results of this study showed that there is a positive relationship between the educational attainment and teaching methods with information and communication technology (10). Swain conducted a study titled the role of simulation software in the educational progress in technical courses. The results indicated the effect of these applications on a student's academic achievement in technical courses (11). Oso et al., conducted another study using titled the effect of computer-assisted instruction compared with the traditional method on the biological performance of final year students in Ghana, quasi-experimental method. The results showed that in the average, those who have using learned computers learned science concepts better than the group received the traditional method (12). In a study entitled multimedia in schools, Elliot investigated the effect of web animation-based teaching on learning science, English language, reading and comprehension in third and fifth and eighth grade high school students. The findings of this study showed that the performance of students trained by multimedia was more than the average level and better than students trained in the traditional manner (13). Another study was conducted by Harrison et al, titled "investigating the effect of ICT in education"; the researchers thus concluded that ICT makes education deeper and more effective, thereby increasing creativity among them (14). In another research conducted by Yongj in relation to the effect of information and communication technology, it was found that ICT enhances learning due to its focus on inclusive learning (15). In connection with the "role of ICT in flexible learning programs in schools", Hirosato and Tien conducted a research and it was found that ICT can be a source for teachers in the flexible teachinglearning process (16). Zameni et al., investigated the effect of the ICT application in learning math course, in which it was mentioned that people who pay tuition to produce educational content and software, lack adequate 
subject knowledge in the field of educational psychology in teaching basic courses and metacognitive discussions; therefore, these applications continue the same style of knowledge transfer; In addition, teachers of basic courses and experts in educational and training issues lack adequate software literacy to design software in accordance with common standards (5). In a study, Sharifi investigated the effect of education in smart schools on creativity, achievement motivation and academic achievement of high school girl students Arak high school second period in 2014 - 2015. The results showed that studying in smart schools had no significant effect on creativity and academic achievement of Arak high school female students, except the educational achievement (8). SoleymanPour, Khalkhali and Reayat Konandeye Falah evaluated the effect of ICT-teaching method in creating sustainable learning Science class in grade three of the guidance school. The result of the study showed that ICT-teaching method was effective sustainable learning (17). In a study, Youssefi, Khatiri and Lak Dashti evaluated the effect of simulation and educational software on learning and recall level of students. The results of this study showed a favorable effect of educational software on the student learning and recalling potential (11). A study was conducted using quasiexperimental design by Fazelian and Saadatmand entitled "investigating the effect of computer-assisted instruction compared with traditional teaching methods on learning English in ninth grade". The results showed positive effects of computer-assisted instruction on the English language learning (18).

In a study, Shobeiri and Attaran investigated the effect of educational programs on the academic achievement and the engagement level of students in third grade physics class. The results of their study showed that the use of computers a significantly enhances student learning, increases their interaction with each other and reinforces their spirit of teamwork (19). In a study, Ahmadi concluded that the use of ICT in teaching in an explanatory manner has a positive effect on the learning motivation and academic achievement of students (20); The results of the study conducted by AlHusseini in relation to evaluation of Arak secondary and guidance schools in the academic year of 2001 - 2012, unfortunately showed that the majority of high school and guidance school teachers don't use electronic content in schools, despite their low number (21). In a study titled "the effective of actively teaching physics on the academic achievement of high school students", Nosrat, Yousef and Liaghatdar concluded that ICTbased method for teaching physics affected the students' academic achievement more than the traditional method (22). In a study titled "status of educational technology in teaching geometry”, Behin-aein stated the views and opin- ions of teachers in the ICT-based teaching. Although the majority of teachers in this study emphasize the usefulness of ICT in teaching - learning process, limitations and problems of ICT use in education were discussed from the viewpoint of teachers. After implementing the questionnaire and reviewing the results, it was found that $60 \%$ and $100 \%$ of mathematics male and female teachers, respectively (total of 90\% mathematics teacher) believed that use of the educational technology will enhance the teachinglearning process of spatial geometry. Meanwhile, the majority of teachers believed that the educational technology is not used optimally in the teaching-learning process, for which teachers have more consensuses on the following reasons: lack of time, lack of schools management support and teachers' lack of familiarity with educational software. But the shortage of computers in schools and appropriate educational software were not referred in this regard. At the end of the questionnaire, some mathematics teachers, raised the issue of lack of fluency in English, which was ignored by the researcher. Investigation mathematics teachers' comments indicated that in their view, the use of educational technology improves the teachinglearning process of the spatial geometry. But for the following reasons, this technology is not used optimally in the teaching-learning process of the spatial geometry: lack of proper planning, the conventional evaluation of teachers' performance, lack of time, lack of mathematics teachers familiarity with existing software, math teachers lack of proficiency in using existing spatial geometry software; lack of long-term planning, lack of schools management support from teachers interested in the use of technology, teachers' lack of proficiency in English; teachers' concern over students' higher mastery level in using software compared with themselves; teachers' concern over lower-level of gratitude and appreciation of students, lack of software developed in Farsi, (23). Heidari, Vaziri and Adli investigated the status of smart schools based on "expanded infrastructure of information technology, multimedia content-based learning environment, developed infrastructure of information technology, computer- integrated system of school management, teachers trained in the ICT field and integrated computer communication with other schools and compared the academic performance and the critical thinking of students with ordinary schools. Results of this study showed that the current status of smart schools in terms of teaching-learning content, ICT infrastructure, trained teachers and computer communication with other school is at low-level and is at optimum level only in component of managers' use of computers. Moreover, there was no significant difference between the performance of students in smart and ordinary schools in terms of critical thinking. But there was a significant dif- 
ference in the educational attainment (24). An overview of the research results indicate that ICT-based teaching could more positively affect the deepening of students' learning and their academic achievement. So, it seems that students who are studying in smart schools should perform better than those studying in ordinary schools. This is the assumption, for the assessment of relationship of which with physics 1 the present study is designed. Therefore, the present study attempts to compare students studying in smart schools with those in ordinary ones. In this study students were compared based on variables such as fluidity (creativity), recalling, academic achievement motivation and academic attainment in physics 1 in order compare the main assumption of this research based on the final results. The results of this research can convince officials to be more accountable and pave the ground for the subsequent research and eventually improve the quality of the special programs in smart schools, particularly in physics.

\subsection{Research Hypotheses}

1. There is a significant difference between smart and ordinary school students in terms of creativity (fluidity) level in physics 1 .

2. There is a significant difference between smart and ordinary school students in terms of recalling in terms of the learned content of physics 1 .

3. There is a significant difference between smart and ordinary school students in terms of the for achievement motivation in physics.

4. There is a significant difference between smart and ordinary school students in terms of academic achievement in physics 1.

\section{Methods}

Since on the one hand, this study was conducted to determine the level of creativity (fluidity), achievement motivation, recalling and academic achievement of students in ordinary and smart schools in physics 1 at the end of the school year; and on the other hand, the effect the independent variable has already been applied and the researcher play no role in its manipulation, so this is a causal-comparative or ex post facto research. The causalcomparative method is a quantitative research, which seeks to explore potential causes and their effects by comparing compares individuals who possess a pattern of behavior or personal characteristics with those who lack or possess little degree of that characteristic (25). Thus, in this study, two-group design with post-test is used. To select the two equal groups, initially, a school was randomly selected from among the smart boys' school, to which the smart ranking was assigned in the city of Arak. Then, a classroom was randomly selected from the first grade classes of this school and all students of this classroom were selected as subjects of this study (a total of 28 students). Inclusion criteria included being the first secondary school students studying in a classroom in a smart school and randomly selected from among the other smart schools in Arak City and being male students of the junior high school of the same level with selected students from a smart school studying in ordinary school. Exclusion criteria included being smart school first grade students and students of other classes of non-peer classes in ordinary schools. In order to select the control group, the school was selected, which was located in the geographic area similar to the smart school. Afterwards, a classroom with students of the same level with the experimental group was selected from first grade school classrooms (in terms of educational level). Moreover, a physics teacher who was in the same level with the experimental group teacher in terms of ranking and graduation rate in the previous year was selected as the control group. Therefore, a class of high school students with the smart ranking $(\mathrm{n}=28)$ and another class of the ordinary high school $(n=28)$ were participated in the study. In both groups, physics was taught by teachers for 9 month includes two 1.5 hour sessions. The physics teacher in the experimental group used ICT-based teaching method and smart school facilities include use of physics1 e-books, physics virtual lab and Internet sites like (Rosh, Chista , Takhtesefid , classroom site, etc.) and Testa software for electronic test. In the same period, the teacher in control group had used the explanatory teaching method without any external hardware and software and had only used textbooks. In the last session of physics classroom, students were evaluated in terms of the mind fluidity and motivation for achievement in physics. Furthermore, a test was conducted in accordance with the objectives of the training course in order to compare the two groups in terms of recalling and academic achievement variables at the time final examinations and to assess the effect of ICT on the factors discussed above. It is noteworthy that before taking tests, the informed consent letter was taken from students. It is worth noting that in order to conduct the present study, the written agreement of the relevant authorities were obtained including the district 2 education, Arak and the related schools.

Data collection tools in this study were:

A) Academic achievement assessment test. This test consists of 20 questions, arranged as descriptive questions with short answer and long answers which were designed in order to fulfill educational objectives and teaching content; the maximum and minimum scores were 20 and 0 in 
this test, respectively. This test was designed and its validity was approved by several physics teachers and was revised by 5 experience physics teachers and five experts in the education and training field. Test-retest method was used to determine the test reliability; thus, 15 subjects were randomly selected and were tested using academic achievement test; Afterwards, another test was taken from them after interval of 15 days and the correlation between scores from both tests were measured. The correlation coefficient was 0.96 , which shows the high reliability rate of the test.

B) Abedi creativity test (26): this test was made by Abedi in Iran in 1994, which contains 60 three choice questions. This test consists of 4 subtests, from which only the fluidity sub-test with 18 questions was intended in the present study. Of course, these items were changed in order to be matched with physics course. The highest score was 54 . To evaluate the test validity, the test questions were reviewed and the validity was confirmed by five experts in the education and training field as well as 5 test questions provides education as well as five physics teachers from high schools in Arak. The test reliability was measured using split-half method and correlation test. The correlation coefficient was calculated 0.95 , which shows the test reliability is high.

C) Hermans' achievement motivation test (27): This questionnaire was made in 1970 by Herman. This questionnaire originally consisted of 92 questions which were prepared based on ten characteristics that distinguish highly motivated individuals from those with low achievement motivation. After the implementation of the test and analysis of questions and calculation of correlation of all questions with the whole test, 29 questions were selected as the final the achievement motivation questionnaire. The questions are given incomplete sentences and in order to integrate the value of the questions, 4 options were given after each question. These options will be graded in terms of achievement motivation intensity from high to low or low to high.

Some questions were presented positively and others negatively. In this study, the above test was reduced to 15 questions. Moreover, questions and options were changed in a way that is commensurate with academic achievement in physics 1 . To verify the validity of the test, questions were given to five professors in education training field as well as five physics teachers from high schools in Arak district 2 .

In connection with reliability coefficient, Cronbach's alpha and split-half methods were used. In Split-half method, Spearman correlation coefficient was used. Cronbach's alpha coefficient was calculated as 0.87 and the reliability coefficients were calculated 0.72 using Spearman Brown, which indicates that the reliability of the test is ap- propriate.

A) Recall assessment test was adopted in order to measure students' recall in sequential physics to include questions related to this field in the final exam designed by the researcher. The final exam consists of 20 questions including descriptive short answer and a long answer questions. In test, about 9 score of total scores was assigned to remembering the lessons content. Analysis of the results of this research was conducted in two descriptive and inferential statistics levels. Based on the research hypotheses, descriptive statistics indices were used (mean, standard deviation) in order to organize and summarize scores and describe sizes obtained from samples. Also, to verify the normality of the data distribution and to examine the differences in the studied groups, Levene test and independent t-test were used, respectively. The statistical operations were performed using SPSS 20 and data were analyzed at significant level of $(\mathrm{P}<0.05)$.

\section{Results}

The results showed that the mean age of male students participated in two groups was 15.5 years old , and average grades in grade three students was almost the same in both groups (the average grades of the experimental and control groups were 17.75 and 17.25 respectively at the significance level of 0.259).

According to Kolmogorov-Smirnov test results listed in Table 1, it was found that data related to fluidity, recall, achievement motivation and academic achievement have natural distribution. Therefore, parametric tests were used to analyze the data.

As data listed in Table 2 shows, there is a significant difference in the fluidity test in the experimental and control groups in favor of the former $(\mathrm{P}=0.027)$. In other words, the fluidity score in physics in ordinary school students was more than that of the smart school students.

Moreover, the data given in the table shows that there is a significant difference in recall test score in favor of the control group $(\mathrm{P}=0.002)$. In other words, the student in the ordinary schools performed better in recalling the physics 1 contents compared with the smart school students. Data related to the achievement motivation variable given in the table shows that there is no significant difference in the average academic achievement test results in the experimental and the control group $(\mathrm{P}=0.09)$. In other words, there is no significant difference in between achievement motivation scores of the group enjoyed traditional teaching method in comparison with the group received ICT-based teaching method.

Data contained in Table 2 also shows that there was no significant difference in the mean achievement test results 
Table 1. Results of the Kolmogorov-Smirnov Test

\begin{tabular}{|c|c|c|c|}
\hline Variable & $\mathbf{N}$ & $\mathbf{F}$ & Sig. \\
\hline Creativity & 56 & 0.94 & 0.33 \\
\hline Recall & 56 & 0.02 & 0.82 \\
\hline Achievement motivation & 56 & 0.53 & 0.46 \\
\hline Academic achievement & 56 & 0.2 & 0.88 \\
\hline
\end{tabular}

Table 2. Results of T-Test to Show the Difference Between First Grade Male Students of Secondary Smart and Ordinary Schools in Physics 1

\begin{tabular}{|c|c|c|c|c|c|c|}
\hline Variable & Group & Average & SD & $\mathbf{T}$ & Degrees of Freedom & Sig. \\
\hline \multirow{2}{*}{ Creativity (fluidity) } & Experimental & 38.14 & 6.27 & \multirow{2}{*}{-2.271} & \multirow{2}{*}{54} & \multirow{2}{*}{0.027} \\
\hline & Control & 41.71 & 5.46 & & & \\
\hline \multirow{2}{*}{ Recall } & Experimental & 4.42 & 1.51 & \multirow{2}{*}{-3.320} & \multirow{2}{*}{54} & \multirow{2}{*}{0.002} \\
\hline & Control & 5.80 & 1.57 & & & \\
\hline $\begin{array}{l}\text { Academic achievement } \\
\text { motivation }\end{array}$ & Control & 41.00 & 3.69 & -1.724 & 54 & 0.09 \\
\hline \multirow{2}{*}{ Academic Achievement } & Experimental & 12.23 & 4.51 & \multirow{2}{*}{-0.875} & \multirow{2}{*}{54} & \multirow{2}{*}{0.395} \\
\hline & Control & 13.25 & 4.36 & & & \\
\hline
\end{tabular}

in the experimental and the control groups $(\mathrm{P}=0.395)$.

In other words, there is no significant difference in between academic achievement scores of the group enjoyed traditional teaching method in comparison with the group received ICT-based teaching method.

\section{Discussion}

The purpose behind this study was to compare the fluidity of mind, recall, achievement motivation and academic achievement of students in secondary smart and ordinary schools in physics 1 in Arak city, Iran. The results showed that the traditional classroom was more effective on the fluidity development in physics than the classroom equipped with the superior educational technology. The results of testing this hypothesis were consistent with the findings of the Sharifi (9) consonant, but in inconsistent with the result of research Harrison et (14). These researchers showed that the application of information technology and communications can trigger creativity in students. To justify this contradiction, as the fluidity relates to quantities of a person's responses to a problem on the one hand; and it is time-consuming to address it on the other hand, it can be said that teachers have more time in the traditional classroom than the smart classrooms and use of smart classrooms facilities is time-consuming based on the previous studies in Iran (23). So, it may be said if the class time is equal, the smart school student will perform better than the ordinary school students in this variable; Of course, this assumption must be tested in an independent research.

The second hypothesis test result showed that ordinary school students performed better than students in smart schools in recalling physics 1content. The results of this research hypothesis may be attributed to the unavailability of appropriate educational software and content physics (5), teacher's unfamiliarity with the electronic content and production methods of application of electronic content as well as their lack of interest in the use of electronic content (22). The results of hypothesis testing on the achievement motivation variable showed that there is no significant difference in between achievement motivation of the group enjoyed traditional teaching method in comparison with the group received ICT-based teaching method. The results of this test were consistent with the study conducted by Sharifi (9). Of course, if five pillars of the smart school i.e. "developed infrastructure of the information technology, multimedia content-based learning environment, developed infrastructure of the information technology, computer-integrated school management system, having teachers trained in the field of ICT and integrated computer communication with other schools," are provided at the standard level equal to smart schools, perhaps we saw more level of achievement motivation in the smart schools compared with the ordinary schools 
in various subjects, including physics. However, unfortunately, the limited results of the previous researches indicate that the current smart schools are distant from the desired level $(5,19,23,24)$. The results of last hypothesis testing showed that there is no significant difference in between academic achievement of the group enjoyed traditional teaching method in comparison with the group received ICT-based teaching method.

The results of testing this hypothesis were consistent with research findings of Anderson, Korrapati; Elliot et al; Harrison; Yongj; Ahmadi, Soleyman pour et al; Youssefi, Khatiri and Lak Dashti (4, 7-10, 13, 16, 19).

Perhaps, by citing to the research findings of Zameni et al., (5), the possible reasons for this lack of consistency is that people who produce the educational content and software have inadequate subject knowledge in the field of educational psychology and are unaware of meta-cognitive issues in teaching physics. Therefore, the final softwares continue the same style of knowledge transfer. However, this result is justified according to the findings of other assumptions in this study.

\section{Acknowledgments}

At the end, the author would like to appreciate all officials working in the education and training field in Arak district 2 and the managers and high school students who participated in the study and supported us in conducting it.

\section{References}

1. Timoe R. Online communication in school. I Edu Technol. 2005;6(3):137-55.

2. Jimoyiannis A, Komis V. Examining teachers' beliefs about ICT in education: Implications of a teacher preparation programme. Teacher development. 2007;11(2):149-73.

3. McFarlane A, Sakellariou S. The role of ICT in science education. Cambridge JEdu. 2002;32(2):219-32.

4. Whelan R. Use of ict in education in the south pacific: Findings of the pacific elearning observatory. Distance Education. 2008;29(1):53-70.

5. Zameni F, Kardan S. Influence application Information and communications technology in learning math (In Persian).JInfb Communicat Technol Edu Sci. 2007;1(1):33-8.

6. Hadjerrouit S. Developing web-based learning resources in school education: A user-centered approach. Interdisciplinary J E-Learning Learn Object. 2010;6(13):115-35.

7. Zoufan S. The use of new technologies in education (In Persian). Tehran: Samt; 2011
8. Alias N, Siraj S, DeWitt D, Attaran M, Nordin AB. Evaluation on the usability of physics module in a secondary school in malaysia: Students' retrospective. Malaysian Online J Edu Technol. 2013;44.

9. Barrow L, Markman L, Rouse CE. Technology's edge: The educational benefits of computer-aided instruction. Am Econ J. 2009;1(1):52-74. doi: 10.1257/pol.1.1.52.

10. Deryakulu D, Buyukozturk S, Ozcinar H. Predictors of academic achievement of studen ICT teachers with different styles. Inter J Human Soc Sci. 2010;5(9):567-73.

11. Yosefi R, Khateari K, Lickdashti A. The effect simulation software on learning \& remind students \& comparisont with the traditional teaching methods (in Persian). ICT in education. 2011;3(10):2-5.

12. Mokhtari A. Study of design principles for educational virtual environment (in Persian). Tehran: Islamic Azad Univ Sci Res; 2011.

13. Elliot S. Multimedia in schools: A study of web-based animation effectiveness Available from: http://center.uoregon.edu.

14. Harrison C, Cavendish S, Comber C, Fisher T, Harrison A, Haw K. The impact of information and communication technologies on pupil learning and attainment. ICT in schools Research and evaluation 2002. Available from: www.dfes.gov.uk/ictinschools.

15. Sharefi A. Approaches and strategies ICT in universities. J Educ Admin. 2006;6(5):23-33.

16. Sharifi A, Imani MN. Identifications of skills required by high school teachers and students to apply ICT. Procedia Soc Behav Sci. 2013;83:8415. doi: 10.1016/j.sbspro.2013.06.158.

17. Soleymanpoor J, Khalkhali A, Rayat Konandeh Falah L. The effect of ICT- based teaching methods in creating sustained learning in experimental science course in third grade secondary school students (in Persian). J Sci Res ICT Educ. 2010;1(2):77-93.

18. Fazelian P, Sadatmand M. Study the effect CAI in compare with traditional method in teaching English in first year in Tehran city high school (in Persian). Growth Teach Language. 2004;5(12):4-10.

19. Shobbir A, Ataran M. Taking advantage of educational software physics II High and its effect on academic achievement and engagement of students in the class (in Persian). Tehran: Teacher Training University in Tehran; 2006.

20. Ahmady K. Compare teaching method discussion with use ICT \& use not of that on learning \& motivation achievement in mathematics course 1 first year high school students Arak district 2 (in Persian). Arak: Arak Azad University; 2011.

21. Alhoseani M. investigation condition middle school \& high school with notice to evaluate indicators in the academic year 2010-2011 (in Persian). Arak: Arak Azad University; 2011.

22. Nosrat F, Yousefi A, Liaghatdar M. Impact technical active instruction physics on academic achievement high school students (in Persian). J Knowled Res Educ. 2010;25:53-64.

23. Bhin Iean N. Educational technology in process teaching-learning space geometry (in Persian). J Growth Mate. 2009;97:26-32.

24. Headari M, Vazeri M, Adli F. The study status of smart schools based on academic performance and standards and compare critical thinking students with school (in Persian). J Inform Commun Technol Edu. 2013;2:149-73.

25. Gall M, Borgh V, Gall J. Qualitative and quantitative research methods in psychology (in Persian). Tehran: SAMT Publication; 2003.

26. Abedi J. Creativity and new ways of measuring it (in Persian).J Psychol Res. 1996;2(2):18-25.

27. Hermans HJ. A questionnaire measure of achievement motivation. Appl Psychol. 1970;54(4):353-63. [PubMed: 5483811]. 